\section{Comparación in vitro del sellado apical entre dos sistemas de obturación termoplastificada: Guttacore y E\&Q Master}

\author{
In vitro comparison of the apical seal \\ between two thermoplastic filling systems: \\ Guttacore and E\&Q Master
}

\begin{abstract}
Resumen
Objetivo: Comparar el sellado apical in vitro de los sistemas de obturación termoplastificada, GuttaCore® y E\&Q Master ${ }^{\circledR}$, desde la perspectiva de microfiltración. Métodos: Cuarenta piezas unirradiculares se instrumentaron con sistema rotatorio e irrigaron con hipoclorito de sodio al 2,5\% y EDTA al 17\%. Las muestras se dividieron en dos grupos $(n=20)$; se obturaron y colocaron en estufa incubadora a $37^{\circ} \mathrm{C}$ y $100 \%$ de humedad durante 3 días. Cada muestra se cubrió con barniz de colores excepto $3 \mathrm{~mm}$ apicales para ser sumergidas en azul de metileno al $2 \%$ por 3 días, y centrifugados por 20 min a $3000 \mathrm{rpm}$. Las muestras se lavaron y fracturaron axialmente para su análisis, mediante fotografías, en el estereomicroscopio. Para el análisis de datos se utilizó la prueba t de Student con un nivel de significancia del 5\%. Resultados: Los valores medios de microfiltración fueron 0,660 mm y 0,825 mm para GuttaCore ${ }^{\circledR}$ y E\&Q Master ${ }^{\circledR}$, respectivamente, no encontrándose diferencias estadísticamente significativas entre ellas $(p=0,525)$. Conclusión: GuttaCore ${ }^{\circledR}$ y E\&Q Master ${ }^{\circledR}$ son sistemas de obturación que ofrecen un buen sellado apical no existiendo diferencia entre ellos.
\end{abstract}

Palabras clave: EDTA; Gutapercha; Hipoclorito de Sodio; Microfiltración.

\section{Artículo Original}

Viviana Marcela Hidalgo Moya 1,a, Isadora Martini Garcia ${ }^{2, b}$, Paola Andrea Mena Silva ${ }^{1,3, c}$, Raquel Esmeralda Guillén Guillén 1,b

1 Universidad Central del Ecuador, Facultad de Odontología. Quito, Ecuador.

${ }^{2}$ Universidade Federal do Rio Grande do Sul. Faculdade de Odontologia. Porto Alegre, Brasil.

3 Universidad Regional Autónoma de los Andes, Facultad de Odontología. Ambato, Ecuador.

a Odontóloga.

b $\mathrm{PhD}$. en Odontología

${ }^{\mathrm{C}}$ Especialista en Estética y Operatoria Dental.

Correspondencia:

Viviana Marcela Hidalgo Moya

Correo electrónico: hidalgovivi90@gmail.com 230201 Av. Chone calle Canadá y México 422 Santo Domingo, Ecuador.

Coautores:

Paola Andrea Mena Silva pao mena100@hotmail.com Isadora Martini Garcia isadora.garcia@ufrgs.br Raquel Esmeralda Guillén Guillén raquelguillenguillen@gmail.com

Conflicto de intereses: Los autores declaran no tener conflictos de interés.

Fuente de financiamiento: Autofinanciado

Fecha de recepción: 29/05/18

Fecha de aceptación: 06/08/18

\begin{abstract}
Objective: Compare in vitro the apical seal of thermoplastic filling systems, GuttaCore $₫$ and E\&Q Master ${ }^{\circledR}$, from the perspective of microfiltration. Methods: Forty single-rooted teeth were instrumented with rotary system and irrigated with $2.5 \%$ sodium hypochlorite and $17 \%$ EDTA. The samples were divided into two groups (20 for each system); sealed and placed in the incubator at $37^{\circ} \mathrm{C}$ and $100 \%$ humidity for 3 days. Each sample was covered with colored varnish except the last 3 apical millimiters to be immersed in $2 \%$ methylene blue for 3 days and centrifuged for $20 \mathrm{~min}$ at $3000 \mathrm{rpm}$. The samples were washed and fractured axially for their analysis in the stereomicroscope by means of photographs. For the data analysis we used the t Student test with a level of significance of 5\%. Results: The mean microfiltration values were $0.660 \mathrm{~mm}$ and $0.825 \mathrm{~mm}$ for GuttaCore and E\&Q Master respectively, no statistically significant differences were found between them ( $p=0.525)$. Conclusion: GuttaCore and E\&Q Master are seal systems that offer good apical sealing, there is no difference between them.
\end{abstract}

Keywords: EDTA; Gutta-Percha; Microfiltration; Sodium Hypochlorite. 


\section{Introducción}

El éxito de la terapia endodóncica depende de un buen diagnóstico, una correcta bioinstrumentación, desinfección y obturación; esta última etapa es la más importante y en la cual se obtiene un sellado hermético y tridimensional del conducto, evitando vías de microfiltración que conduzcan a un posible fracaso de la terapia ${ }^{1-4}$. Microfiltración se define como la capacidad que tienen las bacterias y fluidos orales de penetrar libremente por la interfase entre el material obturador y la pared del conducto; una segunda vía que se presenta es el flujo de las sustancias a través de túbulos abiertos en el extremo apical ${ }^{5-7}$. En los últimos años se han desarrollado sistemas de obturación que utilizan gutapercha termoplastificada, concepto introducido por Yee et al. ${ }^{8}$ Estos sistemas están indicados para la obturación de conductos amplios, con anfractuosidades, istmos y reabsorciones internas ${ }^{9-11}$. Además de producir un alto porcentaje de concentración de gutapercha para el sellado en la porción apical, estableciendo una masa más uniforme ${ }^{12-14}$. Aunque la técnica de condensación lateral es universalmente la más utilizada para realizar estudios comparativos, existen varias técnicas de obturación termoplastificada; como Guttacore® (Dentsply Sirona, Suiza) la cual utiliza un vástago de plástico con gutapercha entrelazada; el entrelazado es un proceso que une un estabilizador a la estructura molecular de la gutapercha. GuttaCore ${ }^{\circledR}$ proporciona una obturación consistente con gutapercha caliente hasta el ápice, sin burbujas y con un ajuste fiable y seguro, debido a que el fuerte núcleo es de gutapercha resulta más fácil de retratar. Este núcleo (obturador) es reblandecido por un horno del mismo sistema ${ }^{15,16}$.

E\&Q Master@ (MetaBiomed, Korea) está compuesto por dos partes, una punta maestra para obturar los primeros $4 \mathrm{~mm}$ apicales utilizando un cono de gutapercha común de acuerdo a la lima final de trabajo, una segunda parte que consta de una pistola programada a $150^{\circ} \mathrm{C}$ o $200^{\circ} \mathrm{C}$ en la cual se introduce pequeñas barras de gutapercha que se reblandecen y es inyectada en el conducto radicular ${ }^{17,18}$.

Estos sistemas han ido ganando terreno en los últimos tiempos; por ello, el objetivo del estudio fue comparar el sellado apical que brindan las técnicas de obturación termoplastificada, GuttaCore $₫$ y E\&Q Master $®$ para encontrar cuál ofrece menos microfiltración en la práctica endodóncica.

\section{Métodos}

El protocolo de estudio fue aprobado por el Comité de Ética de la Universidad Central del Ecuador. Se tomaron radiografías y se seleccionaron 40 dientes unirradiculares que cumplían con los criterios de inclusión como: piezas con ápice formado, sin calcificaciones, sin resorciones internas, longitud no mayor a $18 \mathrm{~mm}$ y raíces rectas de 0 a 5 grados según el ángulo de Schneider, las piezas que no cumplieron estos criterios fueron excluidas del estudio. Toda la muestra se conservó en solución salina al $0,5 \%$ y con una punta de ultrasonido se removió cualquier tejido adherido a la muestra. Se continuó con la preparación química-mecánica de los conductos radiculares en dos fases; la primera con limas preserie y de primera serie hasta llegar a una lima $\mathrm{N}^{\circ} 20$. Terminada esta fase, todas las piezas dentales fueron cortadas a nivel amelocementario con un disco de diamante y abundante irrigación para evitar que los conductos se taponen; se obtuvo una longitud de trabajo final de 16 $\mathrm{mm}$ en todas las muestras.

La segunda fase de la preparación química-mecánica de los conductos se realizó con limas rotatorias ProTaper ${ }^{\circledR}$ (Denstply Maillefer, Suiza) hasta lima final F3. Se efectuó la activación dinámica manual de la solución irrigante de hipoclorito de sodio al 2,5\% y EDTA al 17\%, y se secaron los conductos con puntas capillary.

En la fase de obturación la muestra fue dividida en dos grupos de 20 piezas cada uno; el primer grupo con la técnica GuttaCore® los canales fueron obturados con un cono de gutapercha de igual diámetro y conicidad en el conducto radicular, se colocó una delgada capa de cemento (Adseal) con un cono de gutapercha F3. El portador de la gutapercha se calentó en el horno thermaperp 2 en un rango de 30-60 indicado de acuerdo a la lima final y al sistema rotatorio utilizado, el portador caliente se introdujo en el conducto radicular sin forzar ni girar para evitar extrusiones, el mango del portador se retiró doblándolo a cualquier lado de manera lenta y segura, posterior a esto se procedió a eliminar excesos y se realizó un control radiográfico ${ }^{16}$ (Figura 1A, 1B).

El segundo grupo fue obturado con la técnica E\&Q Master ${ }^{\circledR}$ que consta de dos pasos; primero, se introdujo un cono ProTaper® F3 en el conducto con cemento (Adseal). Con la ayuda de la punta del sistema E\&Q medida a menos $4 \mathrm{~mm}$ de la longitud final, se cortó el exceso del cono de gutapercha obturando así los $4 \mathrm{~mm}$ a nivel apical evitando la extrusión del material. Para finalizar el proceso se cargó la pistola del sistema con una barra de gutapercha, calentando la pistola a $200{ }^{\circ} \mathrm{C}$ con una punta de calibre $23 \mathrm{G}$ y se inyectó $2 \mathrm{~mm}$ de gutapercha en el conducto compactándolo de manera adecuada hasta obturarlo por completo ${ }^{8,18}$ (Figura 2A, 2B).

Para el procesamiento de todas las muestras se almacenó en estufa incubadora a $37^{\circ} \mathrm{C}$ y $100 \%$ de humedad durante 3 días ${ }^{19}$. La entrada al conducto en los dos grupos se selló con resina fluida de fotocurado y cada muestra se cubrió con barniz de colores, dejando libre $3 \mathrm{~mm}$ apicales para realizar el proceso de filtración apical, las muestras fueron colocadas en azul de metileno al $2 \%$ por 3 días, posterior a esto se sometió a centrifugación por $20 \mathrm{~min}$ a $3000 \mathrm{rpm}^{19,20}$. Para eliminar todo el colorante se lavó las muestras con abundante agua destilada, los restos de barniz y azul de metileno fueron retirados con ayuda de una hoja de bisturí ${ }^{21,22}$. Finalmente, las muestras se fracturaron axialmente y se analizaron en el estereomicroscopio a 40x. 

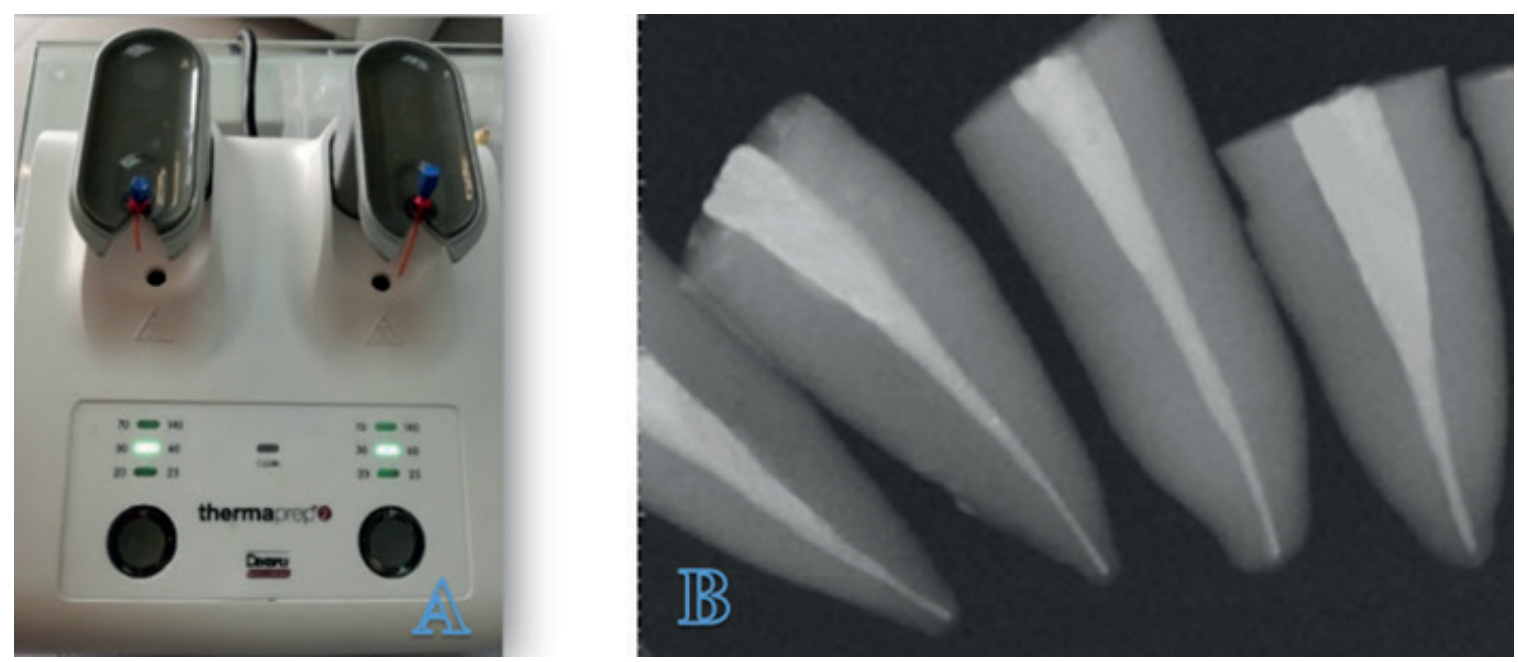

Figura 1. A. Sistema GuttaCore. B. Control radiográfico
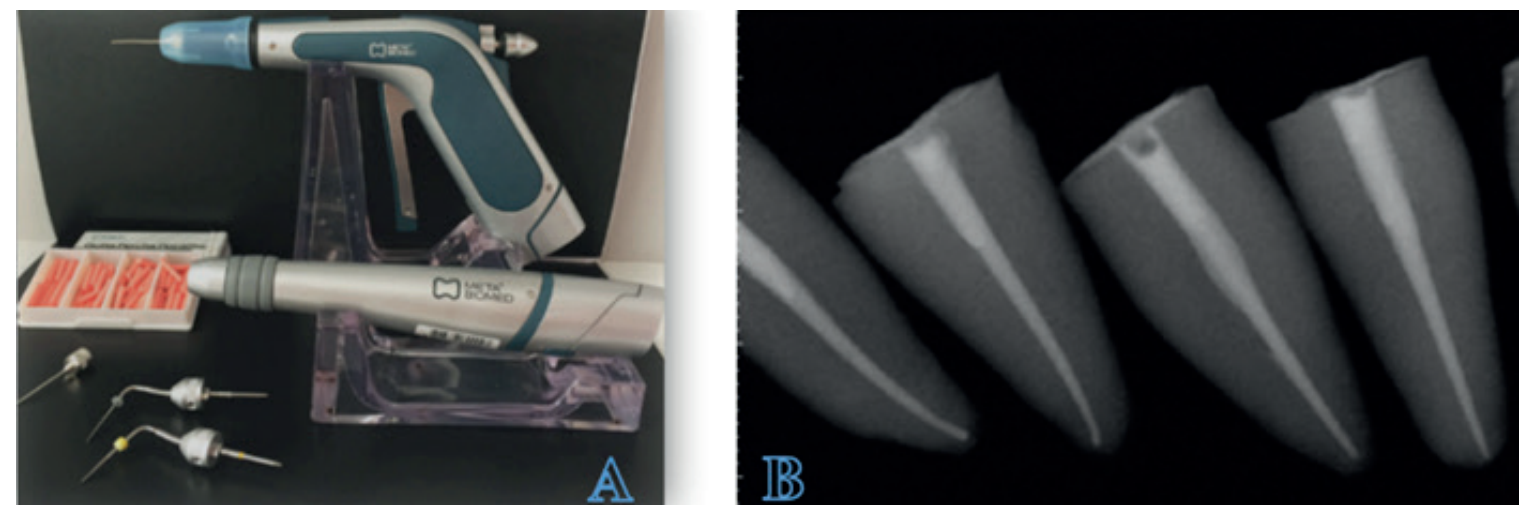

Figura 2. A. Sistema E\&Q Master. B. Control radiográfico

\section{Resultados}

Los datos fueron recolectados, procesados y analizados mediante el uso del office 2016, software estadístico SPSS versión 22.0 y la prueba estadística t de Student para muestras independientes.

Se encontraron valores medios bajos para cada grupo: GuttaCore ${ }^{\circledR}(0,660 \mathrm{~mm})$ y E\&Q Master ${ }^{\circledR}(0,825 \mathrm{~mm})$. Mediante la prueba t de Student para muestras independientes se demostró que no existe diferencia estadísticamente significativa entre GuttaCore $®$ y E\&Q Master $®$; $p=0,525$ (Tabla).

Tabla. Nivel de microfiltración $(\mathrm{mm})$ entre los dos sistemas de obturación

\begin{tabular}{lcccc}
\hline & $\mathbf{n}$ & Media & Desviación estándar & Valor $\mathbf{p}$ \\
\hline Gutta Core Medida & 20 & 0,660 & 0,573 & 0,525 \\
E\&Q Master Medida & 20 & 0,825 & 0,613 & \\
\hline
\end{tabular}

\section{Discusión}

Una obturación endodóncica compactada de manera excelente y adaptada a la perfección produce el cierre total de la interface entre la pared dentinaria con el material, con lo que se obtiene el mejor sellado apical. De esta manera, el tratamiento endodóncico cumple con sus objetivos: eliminar todas las posibles entradas de filtración desde la cavidad oral o de los tejidos perirradiculares ${ }^{3,12}$.

En un estudio previo de Tomer $e t$ al. ${ }^{23}$ donde se comparó la microfiltración apical entre diferentes sistemas de obturación e instrumentación por medio de la penetración de tinte se obtuvo como resultado que Thermafil ${ }^{\circledR}$ y Calamus ${ }^{\circledR}$ presentaron menos microfiltración sin diferencia significativa entre ambos. La técnica de instrumentación no tuvo influencia alguna en los resultados, corroborando de esta manera nuestro estudio al no presentar diferencias significativas entre los sistemas de obturación analizados.

Jamal y Montadher ${ }^{24}$ compararon el tiempo de trabajo y el sellado apical de tres técnicas de obturación utilizando tinta china por 7 días y la diafanización mostró que la técnica de condensación lateral no presentó buen sellado apical en comparación con los otros dos sistemas (Thermafil囚 y E\&Q Master $\left.{ }^{\circledR}\right)$, los cuales no presentaron valores estadísticamente significativos entre ellos mostrando un buen sellado apical, confirmando nuestros resultados al no existir diferencias significativas en el sellado apical de GuttaCore® y E\&Q Master®, a pesar de que la metodología empleada fue diferente.

Callado ${ }^{25}$ en el 2012 utilizó 54 incisivos inferiores instrumentados con ProTaper® Universal y de manera 
aleatoria se dividieron en dos grupos: 27 dientes obturados con Thermafil@ y 27 dientes con Befill $\circledast$, manejado como cemento sellador TopSeal; los resultados obtenidos no presentaron diferencias estadísticamente significativas entre los dos sistemas de obturación. Resultados semejantes se obtuvieron en nuestro estudio utilizando el mismo sistema de instrumentación y como cemento sellador Adseal; por la similitud en la metodología se pudo predecir la inexistencia de discrepancias entre los dos sistemas estudiados, por lo que se podría utilizar solamente el sistema GuttaCore $®$ ya que de acuerdo al grado de microfiltración el valor fue mínimo.

Al comparar los dos sistemas de obturación, E\&Q Master® se presentó de forma más eficiente, ya que se tiene un mayor control en cuanto al reblandecimiento de gutapercha al momento de obturar el tercio apical, así como al rellenar el conducto. Sin embargo, se concluye que no existen diferencias estadísticamente significativas que sobreponga una técnica sobre otra. Los dos sistemas que utilizan gutapercha termoplastificada nos ofrecen un buen sellado apical y un tiempo de trabajo menor a otras técnicas, lo que hace que estos dos sistemas sean ideales para ser utilizados en todo tratamiento endodóncico.

En base a los resultados obtenidos y teniendo en cuenta la metodología empleada se sugiere realizar investigaciones in vitro en las cuales se consideren variables como el tiempo de trabajo, habilidad del operador y simulación de canales laterales, con la finalidad de efectivizar los procesos realizados en una terapia endodóncica. La desventaja de un estudio in vitro es no poder simular las condiciones en que se encuentra la pieza dental en boca, pero permite sugerir la posibilidad de realizar trabajos in vivo que confirmen los resultados obtenidos en este estudio.

\section{Referencias bibliográficas}

1. Choen S. \& Hargreaves K. Vias de la Pulpa. 10ma ed. Estados Unidos: Elsevier Mosbi; 2013.

2. Leonardo M.R. \& Leal J.M. Tratamiento de los conductos radiculares. 2da ed. Buenos Aires: Médica Panamericana; 2009 .

3. Canalda C. \& Brau E. Técnicas Clínicas y Bases Científicas. 2nd ed. Barcelona: Masson; 2014.

4. Torabinejad M. \& Walton, R. Endodoncia Principios y Practica. 4ta ed. Barcelona: Elsevier; 2010.

5. Eraso-Martínez N, Muñoz-Bolaños I. La obturación endodóntica, una visión general. Rev. Nac. Odonto. 2012;8(15):87-94.

6. Monardes H, Abarca J, Castro P. Microfiltración Apical de Dos Cementos Selladores: Un Estudio in vitro. Int. J. Odonto Stomat. 2014;8(3):393-398. Doi: http://dx.doi. org/10.4067/S0718-381X2014000300012

7. Villena, H. Terapia Pulpar en Endodoncia. 1ra ed. Madrid: Ripano,S.A.; 2012.

8. Yee FS, Marlin J, Krakow AA, Gron P. Three-dimensional obturation of the root canal using injection-molded, thermoplasticized dental guttapercha. J Endod.
1977;3(5):168-74. Doi: https://doi.org/10.1016/S00992399(77)80091-5

9. Ortega C, Luis A, Ruiz de Temiño P. Técnicas de obturación en endodoncia. Rev. Esp. Endodoncia. 1987;5(3):91-104.

10. Goldberg F, Soares I.J. Endodoncia tecnicas y fundamentos. 2nd ed. Buenos Aires: Médica Panamericana; 2003.

11. Giudice Garcia A, Torres Navarro J. Obturación en endodoncia - Nuevos sistemas de obturación. Estomatol Herediana. 2011;21(3):166-174.

12. Barzuna U, Cuan M. Obturación con gutapercha termoplastificada. Reporte de dos casos clínicos. Int. J. of Dental Sciences. 2011;12(2):73-80.

13. Bergenholtz G, Hortsed P, Reit C. Endodoncia. 2nd ed. México: Manual Moderno; 2011.

14. Ingle,J. Endodoncia. 5a ed. Mexico: McGraw-Hill-Interamericana; 2004.

15. Valenzuela W. Guttacore, Lo último desarrollado en obturación de canales radiculares. Cl Abto. 2012;8(25):4-7.

16. Dentsply M. Instructivo Gutta-Core. Dentysplay. [Consultado el jueves 3 de febrero 2017]. Accesible en: http://www.dentsplyargentina.com.ar/guttacoreparaPTNdfu.pdf

17. Site A. News Medical - Medical \& Life Sciences. [Consultado el jueves 3 de febrero 2017]. Accesible en: http:// www.news-medical.net/EQ-Master-Cordless-Gutta-Percha-Obturator-from-Meta-BioMed.

18. E\&Q Master Manual. [consultado el jueves 3 de febrero 2017]. Accesible en: https:/www.atlasresell.com/ sites/default/files/E\%26Q\%20Master\%20User's\%20 Manual.pdf

19. Salcedo D, Petkova M, Jara M. Obturation quality assessment of modified Mc Spadden vertical condensation technique, continuos wave thermo plasticized technique an lateral condesation. J Dent (Tehran). 2015;12(2):99-108.

20. Kuçukay I, Kuçukay S, Bayirli G. Factors Affecting Apical Leakage Assessment. J Endod. 1993;19(7):362-5.

21. Pérez-Heredia M, Clavero-González J, Ferrer-Luque CM, González-Rodríguez MP. Apical seal comparison of low-temperature thermoplasticized gutta-percha technique and lateral condensation with two different master cones. Med Oral Patol Oral Cir Bucal 2007;12(3):175-9.

22. Tabares P, García E. Análisis de los métodos de filtración. Cient Dent. 2008;6(1):21-28.

23. Tomer A, Banerjee S, Bhardwaj G, Malik N, Muni S, Rana S. Comparative Evaluation of Apical Microleakage of Various Obturation Techniques using Single Cone Gutta-percha, Lateral Condensation, Obtura, Calamus and Thermafil by Dye Penetration Method. Int J Oral Care Res. 2016;4(1):4-7.

24. Jamal A, Montadher S. Comparison of apical sealability of three obturation techniques (an in vitro study). MDJ. 2012;9(2):130-136.

25. Callado N. Obturacion termoplastica de conductos ovales largos con Thermafil obturadores y Beefill 2 en 1 . Therapeia. 2012;4(3):27-37. 